\title{
An innovation for the goal structure of entrepreneurship education?
}

\author{
Comments on the article of Fritz Oser and Thierry Volery «'Sense of failure' and \\ 'sense of success' among entrepreneurs: the identification and promotion of \\ neglected twin entrepreneurial competencies»
}

\section{Bärbel Fürstenau}

Technische Universität Dresden*

(1) Entrepreneurship education is strongly connected with hope of success on different societal levels: (a) on the national economic level the hope is to generate new jobs and thereby to foster new employment. For this reason we find in many countries entrepreneurship courses or programs at universities, but also - increasingly in the fields of vocational education and training. Different opinions on how to most effectively promote entrepreneurship education compete. However, there seems to be a conviction that graduates as founders provide more employment than non-graduates; (b) on the institutional level one observes that - for example in Switzerland - the percentage of bankruptcy of newly founded firms is constantly about 16 over the last years; (c) on the individual level we observe different behavior in accordance with the successful foundations on the one hand and failure of start-ups on the other hand. Failures can lead in the worst case to a bankruptcy of the whole family. Proper entrepreneurship education programs might lead to the reduction of the percentage of bankruptcies and also to prevent families from economic ruin.

The central question of the authors - a business administrator and an educational psychologist - is which critical overall competencies are needed to launch a sustainable start-up, by which measures the success rate of foundations can be enlarged, and how the negative emotional consequences of failure might be diminished. They develop their concept with regard to the fact that the outcome of educational programs cannot be measured immediately after the end of the courses but - in case a company is actually founded - only in a while after the foundation. Though it is possible to measure the intention to found a company, it is difficult to conclude from the intention to real action. The mostly accepted measure at this moment is given by Ajzen's theory of planned behavior which helps to prognose effectual foundation on the basis of a shown intention by about $27 \%$ probability.

* Bärbel Fürstenau, Lehrstuhl Wirtschaftspädagogik, Technische Universität Dresden, Germany; baerbel. fuerstenau@tu-dresden.de 
(2) Oser and Volery try to overcome these difficulties by proposing a differentiated approach for entrepreneurship education programs: They claim to integrate the two intertwining perspectives of «sense of success» and «sense of failure» as decisive elements of an entrepreneurship education curriculum. The central assumption is that both perspectives have to be taught and learned simultaneously. «Sense of failure» is a construct which can - according to the authors - encompass the following elements: «(a) the basic idea that the start-up might be too weak; (b) difficulties that could emerge with regard to funding; (c) the technology or product design might be flawed; (d) legal difficulties are encountered; and (e) interpersonal and emotional tensions obstruct the way.» By concentrating both on the «sense of failure» and the «sense of success» the authors tackle the fact that the future entrepreneurs must «understand that a business venture might be doomed to failure if just one piece of the 'entrepreneurship puzzle' is missing». In this sense the authors do not want to hinder possible founders to start their business but to sharpen the view for possible negative effects and - also - to strengthen emotional stability.

(3) Oser and Volery give the following reasons for their approach: (a) they stress the large number of foundations which fail; (b) they try to bring more responsibility into current entrepreneurship programs which do not highlight sufficiently possible difficulties with foundations and also personal problems after a failure appeared; (c) they discuss weaknesses of current research which does not elaborate reasons for success or failure sufficiently; in addition, the respective reasons are not related to each other and not compared with each other; (d) they stress the necessity to cope adequately with failure and the connected emotions and thus processes of healing or restoring self-confidence.

For developing a program on how to cope with the «sense of failure» they focus on the importance of a «negative entrepreneur's knowledge» as «a knowledge of and awareness for the fact and the way in which others have failed». Such knowledge has at least three dimensions: (1) risk propensity, responsibility, overconfidence avoidance; (2) awareness for weaknesses and pitfalls, knowledge of how to cope with them; (3) intuition about mistakes, escape heuristics, fear of failure. On the other side Oser and Volery spread out dimensions of «sense of success»: (1) start-up competencies: capacity to discover, evaluate and exploit an opportunity; (2) start-up intention: need for achievement, locus of control, risk taking propensity; (3) start-up expectations: desirability, feasibility, personal benefit.

The importance of the presented approach is given by the fact that in entrepreneurship literature and the corresponding courses «the knowledge and acceptance of a possible failure is largely neglected».

(4) Oser and Volery propose as a consequence of their analyses a well-structured combination of both: «sense of success» and «sense of failure» including also social cognitive self-regulation. The program convinces although some remarks seem necessary to be stressed: 
- The theoretical approach is well embedded into the literature on entrepre neurship education as well as adequate psychological constructs.

- The authors assess «sense of failure» and «sense of success» as two central competence facets of entrepreneurship education curricula. Referring to this, the idea of whether we can only speak about one competence combining both perspectives suggests itself. More research is needed here.

- A central problem is given by the fact that the empirical basis of the approach is at the moment relatively small. This is true with both regard to the amount of studies and the point(s) in time when measurement takes place.

- Corresponding research could focus on the refinement of measuring the degree of intention to found a company against the background of positive and negative knowledge.

- Another topic should be the pair-wise comparison of success and of failure of founders under comparable conditions: branch, products, capital, experience etc.

- Finally, it seems necessary to coach founders who failed by taking into account the consequences for themselves, their families and co-workers.

(5) Summarizing, I judge the presented prospect of bringing together «sense of success» and «sense of failure» for planning, conducting and evaluating programs of entrepreneurship education together with the implementation of corresponding empirical research a fruitful proposal for promoting and supporting founders' effective and efficient behavior. 